\title{
Analisis Faktor Sosiokognitif terhadap Kepatuhan Bidan dalam Penerapan Standar Operasional Prosedur (SOP) Deteksi Dini Pre Eklamsia (di Kecamatan Kenjeran, Semampir, dan Tambaksari)
}

\section{Analysis of Sociocognitive Factors on Midwife Compliance in the Application of Standard Operational Procedure (SOP) for Early Detection Pre Eclampsia (in Kenjeran, Semampir, and Tambaksari Sub-Districts)}

\author{
Riphyana Novayanti* ${ }^{1}$, Efvina Goemawati ${ }^{1}$
}

\begin{abstract}
ABSTRAK
Latar Belakang: Pre eklamsia menjadi salah satu penyebab utama kematian ibu di Provinsi Jawa Timut dengan Angka Kematian Ibu (AKI) Provinsi Jawa Timur pada tahun 2017 mencapai 91,92 per 100.000 kelahiran penduduk. Kota Surabaya tercatat memiliki 72,99 per 100.000 kelahiran penduduk dengan pre eklamsia menjadi salah satu penyebab tingginya Angka Kematian Ibu (AKI). Peran tenaga kesehatan diperlukan untuk menurunkan jumlah kematian ibu di Kota Surabaya.

Tujuan: Tujuan penelitian ini adalah menganalisis faktor sosiokognitif yang mempengaruhi kepatuhan bidan dalam penerapan SOP deteksi dini pre eklamsia di Kecamatan Kenjeran, Semampir, dan Tambaksari.. Metode: Penelitian ini menggunakan crossectional study dengan variabel independen yang terdiri dari individual constraint, intention, organizational constraint, social influence, exemplary behavior, dan facilitating organization serta kepatuhan bidan terhadap penerapan SOP deteksi dini pre eklamsia sebagai variabel dependen. Analisis hubungan penelitian menggunakan cross tabulation dan analisis data menggunakan analisis binary logistic regression.

Hasil: Hasil penelitian menunjukkan variabel individual constraint dan exemplary behavior berpengaruh terhadap kepatuhan penerapan SOP deteksi dini pre eklamsia. Variabel tersebut memiliki p-value lebih kecil dari $\alpha(0,05)$. Selain itu, 28,9\% dari 38 bidan yang dipilih kepatuhannya memiliki kepatuhan rendah terhadap penerapan SOP deteksi dini pre eklamsia, sedangkan 71,1\% lainnya memiliki tingkat kepatuhan tinggi.

Kesimpulan: Faktor sosiokognitif yang berpengaruh dalam penerapan SOP deteksi dini pre eklamsia ialah individual constraint dan exemplary behavior. Oleh karena itu, perlu adanya pembentukan tim untuk pengendalian mutu sebagai upaya pengendalian dari pelaksanaan deteksi dini pre eklamsia agar ketidakpatuhan pada bidan tidak mengalami peningkatan.
\end{abstract}

Kata kunci: deteksi dini pre eklamsia, faktor sosiokognitif, kepatuhan bidan.

\section{ABSTRACT}

Background: Pre-eclampsia is one of the leading causes of maternal mortality in East Java Province. The Maternal Mortality Ratio (MMR) of East Java Province in 2017 reached 91.92 per 100,000 population births. The City of Surabaya recorded 72.99 per 100,000 population births, with pre-eclampsia being one of the causes for the high Maternal Mortality Ratio (MMR). The role of health workers is needed to reduce maternal mortalityin the City of Surabaya.

Objectives: The purpose of this study is to analyze the sociocognitive factors that affect the compliance of midwives in implementing SOP for early detection of pre-eclampsia in the Sub-District of Kenjeran, Semampir, and Tambaksari.

Methods: This study design used a cross-sectional study with sociocognitive factors as independent variables that including individual constraints, intention, organizational constraints, social influence, exemplary behaviour, and facilitating organization as well as midwives compliance with the implementation of SOP early 
detection of pre-eclampsia as the dependent variable. Analysis of the research relationship using crosstabulation and data analysis using binary logistic regression analysis.

Results: The results showed that individual constraint variables and exemplary behaviour affected compliance with SOP application for early detection of pre-eclampsia. This variable has a p-value smaller than $\alpha$ (0.05). In addition, 28.9\% of 38 midwives selected for compliance had low adherence to the implementation of SOP for early detection of pre-eclampsia, while $71.1 \%$ had high levels of commitment.

Conclusions: Sociocognitive factors that influence SOP application for early detection of pre-eclampsia are individual constraints and exemplary behaviour. Therefore, it is necessary to form a team for quality control to control early detection of pre-eclampsia so that non-compliance with midwives does not increase.

Keywords: early detection of pre-eclampsia, midwife compliance, sociocognitive factors

\author{
*Koresponden: \\ riphyananovayanti@gmail.com \\ Riphyana Novayanti \\ ${ }^{1}$ Departemen Administrasi dan Kebijakan Kesehatan, Fakultas Kesehatan Masyarakat, Universitas Airlangga \\ Kampus C Mulyorejo, 60115, Surabaya, Jawa Timur, Indonesia
}

\title{
PENDAHULUAN
}

Angka Kematian Ibu (AKI) dan Angka Kematian Bayi (AKB) merupakan salah satu faktor untuk bisa melihat derajat kesehatan di suatu negara berkembang. Angka Kematian Ibu (AKI) dan Angka Kematian Bayi (AKB) tidak bisa dilepaskan satu sama lain karena saling berhubungan diantara keduanya. Berakhirnya periode Millenium Development Goals (MDGs) 4 (empat) tahun lalu pada tahun 2015 masih menyisakan sejumlah masalah yang harus diselesaikan dalam Sustainable Development Goals (SDGs) atau Tujuan Pembangunan Berkelanjutan (TPB) yang dilaksanakan sampai tahun 2030. Meskipun Millenium Development Goals (MDGs) sudah membawa perubahan di bidang kesehatan, tetapi masih ada target yang belum tercapai seperti Angka Kematian Ibu (AKI), Angka Kematian Bayi (AKB).

Angka Kematian Ibu (AKI) menjadi masalah krusial yang harus segera diselesaikan dan dicari solusi terbaiknya. Oleh karena itu, Indonesia sebagai salah satu negara yang berkomitmen dan sepakat untuk melaksanakan Tujuan Pembangunan Berkelanjutan (TPB) dengan ikut serta menyukseskan pelaksanaan Sustainable Development Goals (SDGs) melalui berbagai kegiatan dan program, khususnya kegiatan dan program di bidang kesehatan. Hal tersebut sesuai dengan tujuan ketiga dari Sustainable Development Goals (SDGs) yang nantinya akan menjamin kehidupan sehat dan meningkatkan kesejahteraan seluruh penduduk Indonesia di semua kalangan usia. Sejalan dengan tujuan ketiga dari Sustainable Development Goals (SDGs), negara Indonesia diharapkan nantinya dapat mencapai target yang ada dan tertuang dalam Sustainable Development Goals (SDGs) dalam menurunkan Angka Kematian Ibu (AKI) kurang dari 70 per 100.000 kelahiran hidup di tahun 2030 (Kementerian Kesehatan Republik Indonesia, 2017).

Angka Kematian Ibu (AKI) di Provinsi Jawa Timur pada tahun 2018 sebesar 91,45 per 100.000 kelahiran hidup. Angka tersebut cenderung menurun dalam 2 (dua) tahun terakhir dimana pada tahun 2017 sebesar 91,92 per 100.000 kelahiran hidup dan di tahun 2016 jumlahnya sebesar 91 per 100.000 kelahiran hidup. Hal tersebut menunjukkan hasil kinerja yang baik dengan adanya dukungan dari program Kesehatan Ibu dan Anak (KIA) dan sistem pencatatan serta sistem pelaporan. Peningkatan keterampilan klinis oleh petugas di lapangan dilaksanakan dengan melibatkan banyak pihak dari Forum Penakib Provinsi Jawa Timur dan Kabupaten/Kota. (Dinas Kesehatan Provinsi Jawa Timur, 2018).

Kota Surabaya merupakan salah satu Kota yang berada dalam wilayah Provinsi Jawa Timur yang belum mencapai target Sustainable Development Goals (SDGs) dengan Angka Kematian Ibu (AKI) kurang dari 70 per

100.00 kelahiran hidup. Kota Surabaya berusaha menurunkan Angka Kematian Ibu (AKI) sesuai dengan target yang telah disepakati pemerintah Indonesia dalam Sustainable Development Goals (SDGs). Angka Kematian Ibu(AKI) di Kota Surabaya cenderung menurun dalam 2 (dua) tahun terakhir, yaitu pada tahun 2016 dan tahun 2017. Meskipun mengalami penurunan, tetap saja belum dikatakan memenuhi target Sustainable Development Goals (SDGs). Peningkatan yang terjadi dalam program Kesehatan Ibu dan Anak (KIA) dilihat dari segi manajemen program maupun sistem pencatatan dan sistem pelaporan dirasa lebih baik dari waktu ke waktu (Dinas Kesehatan Kota Surabaya, 2018).

Kematian ibu di Kota Surabaya secara garis besar disebabkan oleh beberapa faktor, seperti pre eklamsia, perdarahan, infeksi, dan lain-lain yang merupakan penyebab langsung adanya kematian ibu. Sedangkan faktor lain yang berpengaruh ialah penyakit jantung, HIV/AIDS, TB paru, dan hepatitis. Penyebab utama kematian ibu sendiri ialah pre eklamsia (Dinas Kesehatan Kota Surabaya, 2018). Pre 
eklamsia ialah kumpulan gejala yang timbul ketika ibu sedang hamil, bersalin, dan nifas yang terdiri atas trias gejala, yaitu hipertensi protein nuria, edema, dan konfulsi sampai koma serta tidak menunjukkan tanda-tanda vascular atau hipertensi sebelumnya (Festi, 2018). Pre eklamsia menjadi salah satu penyebab utama kematian ibu di Kota Surabaya. Sebagian besar

kematian ibu yang disebabkan oleh pre eklamsia dapat dicegah dan ditangani sejak dini (WHO, 2014). Pencegahan tersebut berupa program deteksi dini pre eklamsia yang harus dikenalkan sejak awal sebagai salah satu tujuan pendekatan risiko pada ibu hamil (Goemawati, 2018).

Program tersebut dilakukan oleh petugas kesehatan di wilayah sekitar, khususnya bidan. Berdasarkan data Profil Dinas Kesehatan Kota Surabaya tahun 2018, kematian ibu tertinggi ada pada wilayah puskesmas di Kecamatan Kenjeran dengan 4 kasus, Kecamatan Semampir dengan 5 kasus, dan Kecamatan Tambaksari dengan 4 kasus kematian. Salah satu upaya yang dilakukan oleh pemerintah Kota Surabaya untuk mengurangi Angka Kematian Ibu (AKI) ialah dengan SOP dalam deteksi dini pre eklamsia di setiap puskesmas di wilayah Kota Surabaya, termasuk wilayah puskesmas di Kecamatan Kenjeran, Kecamatan Semampir, dan Kecamatan Tambaksari yang memiliki jumlah kematian ibu diatas rata-rata. Penetapan SOP deteksi dini pre eklamsia diharapkan dapat dipatuhi oleh petugas kesehatan khususnya bidan. Sehingga, dapat mencegah dan meminimalisir Angka Kematian Ibu (AKI) yang disebabkan karena pre eklamsia (Dinas Kesehatan Kota Surabaya, 2018). Tujuan penelitian ini adalah menganalisis faktor sosiokognitif yang mempengaruhi kepatuhan bidan dalam penerapan SOP deteksi dini pre eklamsia di Kecamatan Kenjeran, Kecamatan Semampir, dan Tambaksari. Hal tersebut terjadi karena faktor sosiokognitif dianggap berpengaruh dalam mengubah perilaku seorang individu.

\section{METODE}

Metode berisi deskripsi yang jelas pada alat dan bahan yang digunakan dan skema penelitian serta metode yang berguna bagi peneliti lainnya untuk melakukan replikasi dan memeriksa validitas jika diperlukan. Referensi harus diberikan pada metode yang digunakan. Studi yang menggunakan subyek hewan atau manusia harus menuliskan bukti etika penelitian yang berlaku.

Penelitian ini termasuk penelitian analitik dengan jenis penelitian bersifat observasional dan dirancang menggunakan cross sectional study, dimana variabel penelitian dilakukan hanya dalam satu waktu. Sehingga diperoleh gambaran keadaan waktu tersebut. Populasi dalam penelitian ini adalah seluruh bidan yang ada di wilayah Kecamatan Kenjeran, Kecamatan Semampir, dan Kecamatan Tambaksari dengan jumlah 57 bidan. Sampel dalam penelitian ini ialah sebagian bidan yang ada di wilayah Kecamatan Kenjeran, Kecamatan Semampir, dan Kecamatan Tambaksari dengan jumlah 38 bidan. Variabel independen dalam penelitian ini ialah faktor sosiokoginitif yang terdiri dari individual constraint, intention, organizational constraint, social influence, exemplary behavior, dan facilitating organization. Sedangkan, variabel dependen dalam penelitian ini adalah kepatuhan bidan dalam penerapan SOP deteksi dini pre eklamsia.

Pengumpulan data primer diperoleh melalui obervasi dan kuesioner. Sedangkan, pengumpulan data sekunder diperoleh melalui skripsi dan Profil Dinas Kesehatan Kota Surabaya serta Profil Dinas Kesehatan Provinsi Jawa Timur. Analisis data dilakukan menggunakan teknik analisis binary logistic regression. Analisis dilakukan untuk menilai pengaruh faktor sosiokognitif berupa individual constraint, intention, organizational constraint, social influence, exemplary behavior, dan facilitating organization terhadap kepatuhan bidan dalam penerapan SOP deteksi dini pre eklamsia.

\section{HASIL DAN PEMBAHASAN}

\section{Kepatuhan Penerapan SOP Deteksi Dini Pre Eklamsia}

Kepatuhan dalam penerapan SOP deteksi dini pre eklamsia terbagi menjadi 2 (dua) kategori, yaitu kategori rendah dan kategori tinggi.

Tabel 1. Tingkat Kepatuhan Penerapan SOP Deteksi Dini Pre Eklamsia di Puskesmas Kecamatan Kenjeran,Semampir dan Tambaksari

\begin{tabular}{lrrr}
\hline & Kepatuhan & $\mathbf{n}$ & \% \\
\hline Rendah & 11 & 28,9 \\
Tinggi & 27 & 71,1 \\
\hline Total & 38 & 100,0 \\
\hline
\end{tabular}


Berdasarkan tabel 1 dapat diketahui bahwa $71,1 \%$ bidan yang berada di wilayah puskesmas Kecamatan Kenjeran, Kecamatan Semampir, dan Kecamatan Tambaksari memiliki tingkat kepatuhan tinggi. Sedangkan, 28,9\% lainnya memiliki tingkat kepatuhan rendah. Mayoritas bidan di Kecamatan Kenjeran, Kecamatan Semampir, dan Kecamatan Tambaksari memiliki tingkat kepatuhan tinggi hal tersebut harus dipertahankan agak lebih baik kedepannya. Sedangkan, bagi sebagian bidan dengan kepatuhan rendah untuk lebih ditingkatkan kepatuhannya guna meminimalisir dan mengurangi kasus pre eklamsia.

Kepatuhan atau compliance dapat diartikan dengan mematuhi suatu aturan, kebijakan, hukum, dan standar yang ditetapkan. Kepatuhan dalam suatu kebijakan menjelaskan mengenai tujuan yang ingin dicapai perusahaan atau organisasi untuk memastikan bahwa mereka telah menjalankan kebijakan atau aturan yang relevan (Nicoletti, 2017). Kepatuhan menurut Notoatmodjo (2012) memiliki 2 (dua) faktor, yaitu faktor internal dan faktor eksternal. Faktor internal dari kepatuhan yang bisa mempengaruhi perilaku kepatuhan seseorang, yaitu persepsi, tingkat pengetahuan atau kecerdaan, minat, emosi dan motivasi. Sedangkan, faktor eksternal dari kepatuhan sendiri, yaitu kelompok dan hasil kebudayaan. Standar Operasional Prosedur (SOP) dari deteksi dini pre eklamsia merupakan bentuk pedoman atau acuan yang digunakan seiring berjalannya pelaksanaan deteksi dini pre eklamsia. Standar Operasional Prosedur (SOP) membantu program untuk mencapai tujuan yang telah ditetapkan dan meminimalisir tingkat kesalahan bidan dalam deteksi dini pre eklamsia.

Faktor Sosiokognitif Penerapan SOP Deteksi Dini Pre Eklamsia

Tabel 2. Faktor Sosiokognitif Penerapan SOP Deteksi Dini Pre Eklamsia di Puskesmas Kecamatan Kenjeran,Semampir dan Tambaksari

\begin{tabular}{lrr}
\hline \multicolumn{1}{c}{ Faktor Sosiokognitif } & n & \% \\
\hline Individual Constraint & 3 & 7,9 \\
Tinggi & 4 & 10,5 \\
Sedang & 31 & 81,6 \\
Rendah & 38 & 100,0 \\
Total & & \\
Intention & 31 & 81,6 \\
Tinggi & 7 & 18,4 \\
Sedang & 0 & 0,0 \\
Rendah & 38 & 100,0 \\
\hline Total & & \\
\hline Organizational Constraint & 5 & 13,2 \\
Tinggi & 7 & 71,1 \\
Sedang & 26 & 15,8 \\
Rendah & 38 & 100,0 \\
\hline Total & & \\
\hline Social Influence & 24 & 63,2 \\
Baik & 14 & 36,8 \\
Cukup & 0 & 0,0 \\
Kurang & 38 & 100 \\
\hline Total & & \\
\hline Exemplary Behavior & 23 & 60,5 \\
Baik & 15 & 39,5 \\
Cukup & 0 & 0,0 \\
Kurang & 38 & 100,0 \\
\hline Total & & \\
\hline Facilitating Organization & 34 & 89,5 \\
Baik & 0 & 0,0 \\
Cukup & 4 & 10,5 \\
Kurang & 38 & \\
\hline Total & & \\
\hline & & \\
\hline
\end{tabular}

Berdasarkan tabel 2 dapat diketahui bahwa nilai individual constraint dalam kategori tinggi sebesar 7,9\%, sedangkan nilai individual constraint dalam kategori rendah sebesar 81,6 yang artinya kendala individu pada bidan dalam pelaksanaan SOP deteksi dini pre eklamsia di Puskesmas Kecamatan Kenjeran, Semampir, dan Tambaksari termasuk rendah. Nilai intention pada bidan dalam kategori tinggi sebesar $81,6 \%$ dan tidak ada bidan dengan nilai intention rendah. Berdasarkan tabel 2 diketahui bahwa nilai 
organizational constraint tertinggi ada pada kategori sedang, yaitu sebesar $71,1 \%$ yang berarti constraint tersebut masih dapat berubah menjadi baik ataupun kurang.

Selain itu, diketahui berdasarkan data dalam tabel 2 bahwa nilai social influence tertinggi sebesar $63,2 \%$ dan tidak ada bidan yang menilai social influence dalam lingkungan kerja mereka rendah. Sedangkan, nilai exemplary behavior dalam kategori tinggi sebesar 60,5\% dan tidak ada bidan yang menilai exemplary behavior mereka rendah. Selanjutnya, nilai facilitating organization dalam pelaksanaan SOP deteksi dini pre eklamsia di Puskesmas Kecamatan Kenjeran, Semampir, dan Tambaksari sudah baik, yaitu sebesar $89,5 \%$. Nilai tersebut memiliki arti bahwa ketersediaan fasilitas atau fasilitas yang ada dan tersedia di instansi/puskesmas terbilang baik.

Faktor sosiokognitif dalam penerapan SOP deteksi dini pre eklamsia di Puskesmas Kecamatan Kenjeran, Kecamatan Semampir, dan Kecamatan Tambaksari terdiri dari 6 (enam) indikator, yaitu individual constraint, intention, organizational constraint, social influence, exemplary behavior, dan facilitating organization. Keenam indikator tersebut memiliki kelebihan dan kekurangan masing-masing terkait dalam penerapan SOP deteksi dini pre eklamsia di Puskesmas Kecamatan Kenjeran, Kecamatan Semampir, dan Kecamatan Tambaksari. Individual constraint atau kendala individu merupakan salah satu faktor yang dimiliki oleh seseorang, baik berupa faktor fisik, atribut yang mempengaruhi gerakan, dan mental, dimana hasil penelitian diketahui bahwa individual constraint menekankan pada keyakinan masingmasing dan bentuk pengetahuan mengenai kendala fungsional dan struktural yang ada. Pengetahuan yang baik diperlukan agar individu data memberikan keputusan dengan tepat. Bidan yang bertugas dinilai memiliki pengetahuan dan keyakinan ketika menerapkan SOP deteksi dini pre eklamsia. Sehingga nilai constraint yang rendah menunjukkan bahwa keyakinan dan pengetahuan bidan di Puskesmas Kecamatan Kenjeran, Kecamatan Semampir, dan Kecamatan Tambaksari tergolong sudah baik. Meskipun demikian, pemahaman yang ada perlu ditingkatkan agar bisa memahami dengan baik dalam penerapan SOP deteksi dini pre eklamsia.

Intention atau niat merupakan salah satu indikator yang menentukan seberapa besar upaya yang akan dilakukan dan seberapa keras seseorang ingin mencoba hal tersebut (Huang, 2009). Niat merupakan awalan penting ketika seseorang akan melakukan suatu kegiatan atau aktivitas yang berpengaruh terhadap dirinya sendiri dan orang lain. Hasil penelitian menunjukkan bahwa mayoritas bidan yang berada di wilayah Puskesmas Kecamatan Kenjeran, Kecamatan Semampir, dan Kecamatan Tambaksari memiliki intention yang tinggi terhadap penerapan SOP deteksi dini pre eklamsia dan tidak ada bidan yang memiliki intention rendah. Hal tersebut dilakukan tanpa membedakan jenis pasien yang sedang atau akan diperiksa dan dalam proses penerapan SOP deteksi dini pre eklamsia intention merupakan dasar utama yang harus ada dan dimiliki oleh bidan dalam menjalankan tugas dan fungsinya di dunia kesehatan.

Organizational constraint atau kendala organisasi merupakan suatu kondisi atau situasi yang menjadi penghambat dan mengganggu pekerjaan dan tugas individu di tempat kerja. Terdapat beberapa kendala yang ada di organisasi menurut Goemawati (2018), yaitu ketersediaan waktu, reward dan juga puisment yang diberikan. Hasil penelitian menunjukkan bahwa penilaian bidan mengenai organizational constraint dalam penerapan SOP deteksi dini pre eklamsia berada dalam kategori sedang. Hal tersebut berarti masih ada sedikit pemahaman yang nilainya dapat meningkat ataupun menurun, karena berada dalam kategori sedang. Oleh karena itu, perlu adanya peningkatan pemahaman terkait penerapan SOP deteksi dini pre eklamsia di Puskesmas Kecamatan Kenjeran, Kecamatan Semampir, dan Kecamatan Tambaksari.

Social influence atau pengaruh sosial merupakan besaran penelitian yang menunjukkan seberapa mudah peserta dipengaruhi oleh pengaruh, penilaian, dan pendapat orang lain (Zaki, Schirmer, dan Mitchell, 2011). Pengaruh sosial terjadi ketika suatu kelompok menginginkan individu atau kelompok lain melakukan hal tertentu. Hasil penelitian menunjukkan bahwa social influence bidan di wilayah Puskesmas Kecamatan Kenjeran, Kecamatan Semampir, dan Kecamatan Tambaksari berada dalam kategori baik, dimana mayoritas bidan menilai bahwa social influence di tempat kerja mereka sudah baik. Social influence bidan sendiri meliputi saran dan hubungan dengan rekan kerja, dimana saran tersebut diberikan sebagai hubungan timbal balik rekan kerja ketika ada yang lupa atau lalai dan hubungan rekan kerja yang baik sebagai bentuk kerja sama tim menjadi salah satu bagian dalam pengaruh sosial. Mekanisme social influence menekankan pada validasi sosial dan hubungan timbal balik dalam penerapan SOP deteksi dini pre eklamsia di Puskesmas Kecamatan Kenjeran, Kecamatan Semampir, dan Kecamatan Tambaksari.

Exemplary behavior merupakan suatu konsep yang menghubungkan perilaku follower dan leader, tugas- tugas, dan tujuan yang dicapai dan dipromosikan. Hasil penilaian menunjukkan bahwa perilaku bidan kepada atasan atau rekan kerjanya dalam penerapan SOP deteksi dini pre eklamsia termasuk dalam kategori baik karena mayoritas bidan menilai exemplary behavior tinggi dan tidak ada bidan yang menilai exemplary behavior mereka rendah. Selain itu, diharapkan ketika dalam penerapan SOP deteksi dini pre eklamsia baik bidan tidak membedakan pasien satu dengan pasien lain, sehingga seluruh sasaran yang akan dilakukan deteksi dini pre eklamsia dapat terlaksana dan terpenuhi dengan baik. 
Facilitating organization membahas mengenai ketersediaan fasilitas yang ada dalam puskesmas tempat kerja bidan. Mengutip dari Peraturan Menteri Kesehatan Nomor 71 Tahun 2013 Tentang Pelayanan Kesehatan Pada Jaminan Kesehatan Nasional, fasilitas ksehatan merupakan suatu pelayanan kesehatan yang digunakan untuk menyelenggarakan upaya pelayanan kesehatan perorangan, baik promotif, preventif, kuratif maupun rehabilitatif yang dlakukan pemerintah, pemerintah daerah dan masyarakat sekitar. Adanya SOP deteksi dini pre eklamsia yang tertempel di dinding tempat kerja bidan merupakan salah satu contoh dari ketersediaan fasilitas di tempat kerja. Hasil penelitian menunjukkan bahwa ketersediaan fasilitas penunjang SOP deteksi dini pre eklamsia di tempat kerja bidan sudah sesuai standar dan tersedia dengan baik, hal tersebut diukur dari ada atau tidaknya SOP deteksi dini pre eklamsia yang tertempel di dinding tempat kerja bidan wilayah Puskesmas Kecamatan Kenjeran, Kecamatan Semampir, dan Kecamatan Tambaksari.

Individual constraint atau kendala individu adalah suatu kendala yang saling bertentangan dalam agensi manusia dan dijelaskan sebagai kapasitas yang dimiliki individu untuk bertindak secara mandiri dalam membuat pilihan (Haywood dan Getchell, 2014). Sesuai dengan hasil analisis dari tabulasi silang antara individual constraint dengan kepatuhan penerapan SOP deteksi dini pre eklamsia menunjukkan bahwa semakin rendah nilaiindividual constraint pada bidan, maka semakin tinggi kepatuhan bidan tersebut dalam menerapkan SOP deteksi dini pre eklamsia.

Intention atau niat dijelaskan sebagai tujuan atau rencana yang harus direalisasikan. Niat menjelaskan beberapa faktor motivasi yang berdampak kuat kepada tingkah laku Tingkah laku tersebut dilakukan berdasarkan niat dan ditunjang dengan keyakinan yang dimiliki seseorang (Lestarina, 2018). Berdasarkan hasil tabulasi silang antara intention dan kepatuhan bidan dalam penerapan SOP deteksi dini pre eklamsia, dketahui bahwa semakin tinggi intention yang dimiliki maka semakin tinggi pula tingkat kepatuhan dalam penerapan SOP deteksi dini preeklamsia.

Organizational constraint adalah suatu keadaan dan kondisi atau situasi di tepat kerja yang bisa menghambat dan mengganggu kinerja seseorang, dalam penelitian ini yang dimaksud ialah bidan. Selain itu, ketegangan karyawan juga sebagai pemicu adanya kendala dalam organisasi (Pindek dan Spector, 2016). Berdasarkan hasil tabulasi silang organizational constraint dan kepatuhan penerapan SOP deteksi dini pre eklamsia pada bidan, diketahui bahwa semakin rendah organizational_constraint yang terjadi pada bidan maka semakin tinggi tingkat kepatuhan bidan tersebut dalam menerapkan SOP deteksi dini pre eklamsia.

Social influence berhubungan dengan pengaruh dari kehadiran orang lain disekitar kita, termasuk individu, kelompok dan kepatuhan terhadap kewenangan. Pengaruh sosial yang ada pada bidan dapat dinilai dari atasan ataupun bawahan dan berdasarkan hasil tabulasi silang yang telah dilakukan antara social influence dengan kepatuhan penerapan SOP deteksi dini pre eklamsia, diketahui bahwa semakin tinggi social influence maka semakin tinggi pula tingkat kepatuhan bidan untuk menerapkan SOP deteksi dini pre eklamsia di Puskesmas Kecamatan Kenjeran, Kecamatan Semampir, dan Kecamatan Tambaksari.

Examplary behavior menjadi salah satu hal perilaku yang patut diteladani dan mengacu pada komitmen pribadi seseorang terhadap nilai, identitas, dan tujuan yang dipromosikan dan diperjuangkan. Berdasarkan analisis yang diperoleh dari hasil tabulasi silang antara kepatuhan bidan dalam penerapan SOP deteksi dini pre eklamsia dengan exemplary behavior, maka diketahui bahwa tingginya exemplary behavior yang ada pada bidan berpengaruh terhadap tingginya tingkat maka semakin kepatuhan bidan terhadap penerapan SOP deteksi dini pre eklamsia.

Facilitatiing organization membahas mengenai ketersediaan fasilitas yang ada pada tempat kerja bidan. Hal mudah yang bisa dilakukan, yaitu melihat ada atau tidak adanya SOP deteksi dini pre eklamsia yang tertempel di dinding bidan tersebut. Ketersediaan fasilitas menjadi indikator terakhir dari faktor sosiokognitif yang berpengaruh terhadap kepatuhan penerapan SOP deteksi dini pre eklamsia. Tabulasi silang antara facilitatiing organization dan kepatuhan dalam penerapan SOP deteksi dini pre eklamsia menunjukkan bahwa semakin tinggi nilai darifacilitating organization di tempat kerja bidan, maka semakin tinggi pula tingkat kepatuhan bidan terhadap penerapan SOP deteksi dini pre eklamsia.

Tabel berikut merupakan penjelasan hasil tabulasi silang (cross tabulation) yang berasal dari analisis faktor sosiokognitif terhadap kepatuhan bidan dalam penerapan SOP deteksi dini pre eklamsia di Puskesmas Kecamatan Kenjeran, Semampir, dan Tambaksari: 
Faktor Sosiokognitif Terhadap Kepatuhan Bidan Dalam penerapan SOP Deteksi Dini Pre Eklamsia

Tabel 3. Faktor Sosiokognitif Terhadap Kepatuhan Bidan Dalam Penerapan SOP Deteksi Dini Pre Eklamsia diPuskesmas Kecamatan Kenjeran, Semampir dan Tambaksari

\begin{tabular}{|c|c|c|c|c|}
\hline \multirow{3}{*}{$\begin{array}{c}\text { Faktor } \\
\text { Sosiokognitif }\end{array}$} & \multicolumn{4}{|c|}{ Kepatuhan } \\
\hline & \multicolumn{2}{|c|}{ Tinggi } & \multicolumn{2}{|c|}{ Rendah } \\
\hline & $\mathbf{n}$ & $\%$ & $\mathbf{n}$ & $\%$ \\
\hline \multicolumn{5}{|c|}{ Individual Constraint } \\
\hline Tinggi & 1 & 33,3 & 2 & 66,7 \\
\hline Sedang & 1 & 25,0 & 3 & 75,0 \\
\hline Rendah & 25 & 80,6 & 6 & 19,4 \\
\hline Total & 27 & 71,1 & 11 & 28,9 \\
\hline \multicolumn{5}{|l|}{ Intention } \\
\hline Tinggi & 23 & 74,2 & 8 & 25,8 \\
\hline Sedang & 4 & 57,1 & 3 & 42,9 \\
\hline Rendah & 0 & 0,0 & 0 & 0,0 \\
\hline Total & 27 & 71,7 & 11 & 28,9 \\
\hline \multicolumn{5}{|c|}{ Organizational Constraint } \\
\hline Tinggi & 4 & 80,0 & 1 & 16,7 \\
\hline Sedang & 18 & 66,7 & 9 & 33,3 \\
\hline Rendah & 5 & 83,3 & 1 & 20,0 \\
\hline Total & 27 & 71,1 & 11 & 28,9 \\
\hline \multicolumn{5}{|l|}{ Social Influence } \\
\hline Baik & 17 & 70,8 & 7 & 29,2 \\
\hline Cukup & 10 & 71,4 & 4 & 28,6 \\
\hline Kurang & 0 & 0,0 & 0 & 0,0 \\
\hline Total & 27 & 71,1 & 11 & 28,9 \\
\hline \multicolumn{5}{|c|}{ Exemplary Behavior } \\
\hline Baik & 19 & 82,7 & 4 & 17,3 \\
\hline Cukup & 8 & 53,3 & 7 & 46,7 \\
\hline Kurang & 0 & 0,0 & 0 & 0,0 \\
\hline Total & 27 & 71,1 & 11 & 28,9 \\
\hline \multicolumn{5}{|c|}{ Facilitating Organization } \\
\hline Baik & 25 & 73,5 & 9 & 26,5 \\
\hline Cukup & 2 & 50,0 & 2 & 50,0 \\
\hline Kurang & 0 & 0,0 & 0 & 0,0 \\
\hline Total & 27 & 71,1 & 11 & 28,9 \\
\hline
\end{tabular}

Diketahui berdasarkan tabel 3 yang memuat data mengenai faktor sosiokognitif dengan tingkat kepatuhan bidan, bahwa semakin tinggi nilai dari individualconstraint, maka semakin rendah kepatuhan bidan terhadap penerapan SOP deteksi dini pre eklamsia. Hal tersebut menunjukkan bahwa constraint pada bidan dapat menurunkan tingkat kepatuhan bidan dalam penerapan SOP deteksi dini pre eklamsia. Berdasarkan tabel 3 semakin tinggi intention seseorang, maka semakin tinggi kepatuhan bidan terhadap penerapan SOP deteksi dini pre eklamsia. Selain itu, semakin tinggi nilai organizational constraint, maka semakin rendah tingkat kepatuhan bidan terhadap penerapan SOP deteksi dini pre eklamsia.

Bagian dari faktor sosiokognitif selanjutnya ialah social influence. Semakin baik social influence seorang bidan, maka semakin tinggi tingkat kepatuhan bidan terhadap penerapan SOP deteksi dini pre eklamsia. Kemudian jika dilihat berdasarkan tabel 3 diketahui bahwa semakin baik exemplary behavior maka semakin tinggi pula tingkat kepatuhan bidan terhadap penerapan SOP deteksi dini pre eklamsia.

Sementara itu, jika dilihat dari variabel facilitating organization, dimana semakin baik facilitating organization, maka semakin tinggi pula tingkat kepatuhan bidan terhadap penerapan SOP deteksi dini pre eklamsia. Tingginya nilai facilitating organization dilihat dari fasilitas yang ada pada instansi atau puskesmas yang sudah terbilang baik.Uji pengaruh dari beberapa variabel dilakukan setelah proses tabulasi silang (cross tabulation). Suatu variabel dianggap berpengaruh apabila memiliki p- value atau signifikansi lebih kecil dari $\alpha$, dimana $\alpha$ dalam hal ini bernilai 0,05 . Berikut ini merupakan hasil uji pengaruh dari faktor sosiokognitif: 


\section{Hasil Uji Pengaruh Faktor Sosiokognitif Terhadap Kepatuhan Bidan Dalam Penerapan SOP Deteksi DiniPre Eklamsia}

Tabel 4. Hasil Uji Pengaruh Faktor Sosiokognitif Tethadap Kepatuhan Bdan Dalam Penerapan SOP DeteksiDini Pre Eklamsia di Puskesmas Kecamatan Kenjeran, Semampir dan Tambaksari

\begin{tabular}{lcc}
\hline \multicolumn{1}{c}{ Variabel } & Sig & Keterangan \\
\hline Individual Constraint & 0,044 & Signifikan \\
Intention & 0,504 & Tidak Signifikan \\
Organizational Constraint & 0,992 & Tidak Signifikan \\
Social Influence & 0,063 & Tidak Signifikan \\
Exemplary Behavior & 0,039 & Signifikan \\
Facilitating Organization & 0,104 & Tidak Signifikan \\
\hline
\end{tabular}

Berdasarkan tabel 4 dapat diketahui bahwa variabel yang berpengaruh terhadap kepatuhan penerapan Standar Operasional Prosedur (SOP deteksi dini pre eklamsia oleh bidan ialah variabel individual constraint dan exemplary behavior. Hal tersebut diketahui dari variabel individual constraint yang memiliki p-value atau signifikansi sebesar 0,044. Suatu variabel dapat dikatakan signifikan apabila nilai atau signifikannya lebih kecil dari $\alpha$ atau nilainya lebih kecil dari 0,05 dengan kesimpulan Ho ditolak, yang berarti variabel individual constraint dianggap berpengaruh terhadap kepatuhan penerapan SOP deteksi dini pre eklamsia.Variabel exemplary behavior jika dilihat dari tabel 4, memiliki p- value atau signifikansi sebesar 0,039. Nilai tersebut dapat dikatakan signifikan karena nilainya lebih kecil dari $\alpha$ atau lebih kecil dari 0,05, yang berarti memiliki kesimpulan Ho ditolak. Variabel exemplary behavior dianggap berpengaruh terhadap kepatuhan penerapan SOP deteksi dini pre eklamsia.

Berdasarkan hasil pengukuran kepatuhan bidan di Puskesmas Kecamatan Kenjeran, Kecamtan Semampir, dan Kecamatan Tambaksari yang menunjukkan bahwa 28,9\% bidan memiliki tingkat kepatuhan terhadap SOP deteksi dini pre eklamsia rendah. Mengutip dari prinsip pareto yang menjelaskan bahwa $80 \%$ masalah disebabkan oleh $20 \%$ penyebab masalah (Husni dan Putra, 2018). Hal tersebut sesuai dengan hasil pengukuran bidan sebanyak $28,9 \%$ bidan memiliki tingkat kepatuhan rendah terhadap SOP deteksi sini pre eklamsia. Oleh karena itu, dikhawatirkan hal tersebut memberi dampak negatif dalam pelaksanaan SOP deteksi dini pre eklamsia di Puskesmas Kecamatan Kenjeran, Kecamatan Semampir, dan Kecamatan Tambaksari. Kepatuhan sendiri merupakan salah satu bentuk dari perilaku seseorang yang nantinya mempengaruhi perilaku orang tersebut. Kepatuhan bidan dalam penerapan SOP deteksi dini pre eklamsia akan memberikan gambaran pelayanan kesehatan yang seharusnya diperoleh oleh ibu hamil selama masa kehamilan, melahirkan dan nifas (Goemawati, 2018).

Hasil uji pengaruh dari individual constraint menunjukkan hasil yang signifikan atau berpengaruh dengan nilai signifikansi 0,044, dikatakan signifikan karena nilai tersebut kurang dari $\alpha 0,05$. Selain itu, indikator lain yang diuji dalam penelitian kali ini yaitu intention, dimana hasil uji pengaruhnya menunjukkan nilai 0,504 dimana nilai tersebut lebih besar dari $\alpha 0,05$ dan hasil yang dipeorleh yaitu tidak signifikan atau tidak berpengaruh Selanjutnya ialah indikator organizational constraint yang menunjukkan tidak adanya pengaruh atau tidak signifikan, karena memiliki nilai sebesar 0, 992 (lebih besar dari $\alpha$ 0,05). Beberapa variabel yang memiliki nilai tidak signifikan, seperti organizational constraint, intention, dan facilitating organization tetap saja dikhawatirkan dapat mempengaruhi kepatuhan bidan dalam penerapan SOP deteksi dini pre eklamsia nantinya. Hal tersebut dikarenakan social influence dengan kategori cukup memiliki hasil kepatuhan lebih tinggi dibandingkan dengan social influence yang baik. Hal ini menunjukkan bahwa nantinya social influence dapat semakin baik ataupun semakin buruk. Disisi lain, semakin baik facilitating organization maka kepatuhan bidan dalam penerapan SOP deteksi dini pre eklamsia akan semakin tinggi. Hal ini menunjukkan bahwa fasilitas yang baik dapat menjadikan seseorang memiliki kepatuhan yang tinggi dalam melaksanakan aktivitas tertentu, sama halnya dengan Organizatonal Constraint, dimana semakin rendah kendala yang ada pada organisasi, maka kepatuhan akan semakin tinggi. Disamping itu, intention bidan dala menerapkan SOP deteksi dini pre eklamsia belum menunjukkan pengaruh yang signifikan, namun semakin tinggi intention yang diberikan untuk pelaksanaan SOP deteksi dini pre eklamsia maka akan semakin tinggi pula kepatuhan bidan dalam penerapan SOP deteksi dini pre eklamsia. Guna mendukung dan meningkatkan kepatuhan agar menjadi lebih baik, maka bisa dilihat dari variabel exemplary behavior seperti pada perilaku atasan dan rekan kerja menerapkan tahapan SOP deteksi dini pre eklamsia dengan baik dan tepat dimana hal tersebut dapat dicontoh penerapannya oleh bidan. Selain itu, pada variabel individual constraint lebih menekan kan pada bentuk pengetahuan dan keyakinan pribadi dalam menjalankan SOP deteksi dini pre eklamsia. Oleh karena itu, perlu adanya peningkatan dalam memahami tahapan-tahapan dalam SOP deteksi dini pre eklamsia. 


\section{KESIMPULAN}

Faktor social influence dalam penerapan SOP deteksi dini pre eklamsia di wilayah Puskesmas Kecamatan Kenjeran, Kecamatan Semampir, dan Kecamatan Tambaksari menunjukkan kategori baik. Faktor individual constraint menunjukkan kendala rendah yang artinya faktor tersebut dapat dikatakan dalam kategori baik. Faktor organizational constraint berada dalam kategori sedang dan mayoritas bidan memiliki intention yang tinggi dalam penerapan SOP deteksi dini pre eklamsia. Selain itu, social influence dalam penerapan SOP deteksi dini pre eklamsia menunjukkan kategori baik, exemplary behavior bidan mayoritas baik, dan facilitating organization di tempat kerja bidan termasuk dalam kategori baik. Oleh karena itu, dapat dikatakan bahwa kepatuhan bidan dalam penerapan SOP deteksi dini pre eklamsia di wilayah Puskesmas Kecamatan Kenjeran, Kecamatan Semampir, dan Kecamatan Tambaksari belum sepenuhnya tinggi sehingga perlu adanya solusi atau inovasi baru yang harus diterapkan.

Perlu adanya intention yang baik pada bidan untuk menerapkan SOP deteksi dini eklamsia. Rekan kerja dapat memberikan saran atau masukkan yang berpengaruh untuk membantu bidan dalam menerapkan SOP deteksi dini pre eklamsia sesuai dengan variabel social influence. Disisi lain, kepatuhan atasan dalam menerapkan SOP deteksi dini pre eklamsia juga dapat menjadi exemplary behavior. Disamping itu, guna memudahkan bidan dalam menerapkan SOP, maka perlu adanya dokumen SOP deteksi dini pre eklamsia yang menjadi bagian dari facilitating organization. Pemberian reward atau punishment dapat diterapkan apabila telah menerapkan SOP deteksi dini pre eklamsia dengan baik atau bahkan tidak menerapkannya sama sekali. Hal tersebut erat kaitanyya dengan organizational constraint. Pembentukan tim dalam pelaksanaan pengendalian mutu dibutuhkan sebagai upaya pengendalian dari pelaksanaan deteksi dini pre eklamsia agar ketidakpatuhan yang terjadi pada bidan tidak mengalami peningkatan. Selain itu, pelatihan khusus pada bidan mengenai deteksi dini pre eklamsia berfungsi untuk meningkatkan keterampilan individu mapun kelompok dalam penerapan SOP deteksi dini pre eklamsia secara menyeluruh dengan detail. Disisi lain, perlu adanya pelaksanaan Training Of Trainer (TOT) oleh puskesmas kepada bidan sebagai bentuk kerja sama tim guna meningkatkan exemplary behavior yang ada dalam lingkup organisasi. Disamping itu, puskesmas perlu melakukan inovasi guna meningkatkan pengetahuan bidan dalam berkomunikasi sebagai bekal untuk menurunkan individual constraint ketika menangani kasus terkait penerapan SOP deteksi dini pre eklamsia.

\section{ACKNOWLEDGEMENT}

Peneliti mengucapkan terimakasih kepeda seluruh pihak yang telah mengijinkan peneliti untuk melakukan penelitian.

\section{REFERENSI}

Badan Pusat Statistik. 2015. Profil Penduduk Indonesia Hasil SUPAS 2015. Jakarta: Badan PusatStatistik. Dinas Kesehatan Kota Surabaya. 2018. Profil Dinas Kesehatan Kota Surabaya Tahun 2018. Surabaya: Dinas. Kesehatan Kota Surabaya.

Dinas Kesehatan Provinsi Jawa Timur. 2018. Profil Dinas Kesehatan Provinsi Jawa Timur Tahun 2018.. Surabaya: Dinas Kesehatan Provinsi Jawa Timur.

Festi, Pipit. 2018. Buku Ajar Gizi Dan Diet. Surabaya: UMSurabaya Publishing.

Goemawati, Efvina. 2018. Faktor Yang Mempengaruhi Kepatuhan Bidan Terhadap PelaksanaanDeteksi Dini. Pre Eklamsia. Skripsi, Fakultas Kesehatan Masyarakat Universitas

a, Surabaya.

Airlangg

Haywood, Kathleen M. dan Getchell, Nancy. 2014. Life Span Motor Development. United States: Human. Kinetics.

Huang, Yu-Chin. 2009. Examining The Antecedents Of Behavioral Intentions In A Tourism Context.. (Doctoral Dissertation, Texas A\&M University, Texas). Diakses dari.https://oaktrust.library.tamu.edu/hndle/1969.1/ETD-TAMU-200905498.

Husni, Amir dan Putra, MGS. 2018. Pengendalian Mutu Hasil Perikanan. Yogyakarta: UGM Press.

Kementerian Kesehatan Republik Indonesia. 2013. Peraturan Menteri Kesehatan Nomor 71 Tahun 2013. Tentang Pelayanan Kesehatan Pada Jaminan Kesehatan Nasional. Jakarta: Kementerian

Kesehatan RI.

Kementerian Kesehatan Republik Indonesia. 2017. Keberhasilan KB Dapat Turunkan Angka KematianIbu. Jakarta: Kementerian Kesehatan RI. 
Lestarina, Ni N. 2018. Theory Of Planned Behavior Sebagai Upaya Peningkatan Kepatuhan Pada Klien Diabetes Mellitus. Jurnal MKMI, 14(2). Diakses dari https://media.neliti.com/media pblications/261153-none 33226f4f.pdf.

Nicoletti, Bernardo. 2017. The Future Of FinTech. London: Palgrave Macmillan.

Notoatmodjo. 2005. Promosi Kesehatan dan Perilaku Kesehatan. Jakarta: Rineka Cipta.

Pindek, S. dan Spector, P. E. 2016. Organizational Constraints: A Meta-Analysis Of A Major Stressor. APA PsycNET, 30(1), Diakses dari https://psycnet.apa.org/record/216-08410-002.

World Health Organization. 2014. Maternal Mortality. World Health Organization.

Zaki, J. et al. 2011. Social Influence Modulates The Neural Computation Of Value. PubMed, 22(7), Diakses dari https://www.ncbi.nlm.nih.gov/pbmed/21653908. 